\title{
BMJ Open Out-of-hospital cardiac arrests in the city of Cape Town, South Africa: a retrospective, descriptive analysis of prehospital patient records
}

\author{
Willem Stassen (D) , ${ }^{1}$ Craig Wylie, ${ }^{1,2}$ Therese Djärv, ${ }^{3}$ Lee A Wallis (D) ${ }^{1}$
}

To cite: Stassen W, Wylie C, Djärv T, et al. Out-of-hospital cardiac arrests in the city of Cape Town, South Africa: a retrospective, descriptive analysis of prehospital patient records. BMJ Open 2021;11:e049141. doi:10.1136/ bmjopen-2021-049141

- Prepublication history for this paper is available online. To view these files, please visit the journal online (http://dx.doi. org/10.1136/bmjopen-2021049141).

Received 16 January 2021 Accepted 04 August 2021

Check for updates

(c) Author(s) (or their employer(s)) 2021. Re-use permitted under CC BY-NC. No commercial re-use. See rights and permissions. Published by BMJ.

${ }^{1}$ Division of Emergency Medicine, University of Cape

Town, Cape Town, South Africa

${ }^{2}$ Division of Emergency

Medicine, Stellenbosch

University, Stellenbosch, South Africa

${ }^{3}$ Department of Medicine,

Karolinska Institutet, Stockholm, Sweden

Correspondence to

Dr Willem Stassen;

willem.stassen@uct.ac.za

\section{ABSTRACT}

Objectives While prospective epidemiological data for out-of-hospital cardiac arrest (OHCA) exists in many highincome settings, there is a dearth of such data for the African continent. The aim of this study was to describe OHCA in the Cape Town metropole, South Africa.

Design Observational study with a retrospective descriptive design.

Setting Cape Town metropole, Western Cape province, South Africa.

Participants All patients with OHCA for the period 1 January 2018-31 December 2018 were extracted from public and private emergency medical services (EMS) and described.

Outcome measures Description of patients with OHCA in terms of demographics, treatment and short-term outcome.

Results A total of 929 patients with OHCA received an EMS response in the Cape Town metropole, corresponding to an annual prevalence of 23.2 per 100000 persons. Most patients were adult $(\mathrm{n}=885 ; 96.5 \%)$ and male $(\mathrm{n}=526 ; 56.6 \%)$ with a median (IQR) age of 63 (26) years. The majority of cardiac arrests occurred in private residences $(n=740 ; 79.7 \%)$ and presented with asystole $(n=322 ; 34.6 \%)$. EMS resuscitation was only attempted in $7.4 \%(n=69)$ of cases and return of spontaneous circulation (ROSC) occurred in $1.3 \%(n=13)$ of cases. Almost all patients $(n=909 ; 97.8 \%)$ were declared dead on the scene.

Conclusion To our knowledge, this was the largest study investigating OHCA ever undertaken in Africa. We found that while the incidence of OHCA in Cape Town was similar to the literature, resuscitation is attempted in very few patients and ROSC-rates are negligible. This may be as a consequence of protracted response times, poor patient prognosis or an underdeveloped and under-resourced Chain of Survival in low- to middle-income countries, like South Africa. The development of contextual guidelines given resources and disease burden is essential.

\section{INTRODUCTION}

Out-of-hospital cardiac arrest (OHCA), defined as the cessation of cardiac mechanical activity that occurs outside of the hospital setting, has emerged as a leading cause of death globally and carries a high mortality. ${ }^{1-6}$

\section{Strengths and limitations of this study}

- This study represents the largest study of out-ofhospital cardiac arrest published in Africa.

- In the absence of an out-of-hospital cardiac arrest registry in South Africa, this study is limited by the retrospective design and under-reproting of important Utstein variables.

- This study is also limited by external validity as it only represents incidents of out-of-hospital cardiac arrest in one South African city.

In high-income countries survival from OHCA has been reported to be between $4.3 \%$ and $11 \% .{ }^{15-9}$ The incidence of OHCA ranges from 28.3 per 100000 in Asia to 54.6 per 100 000 population in North America. ${ }^{7}$ African data suggest an incidence of 6.4 per 100000 population. However, this is likely underestimated, as this particular study limited the sample to OHCA cases attended to by paramedic students. ${ }^{2}$

While African data are sparse, data from other low-resource settings show dramatically worse survival rates in settings where OHCA chains of care are immature or absent, and under-resourced. ${ }^{10-12}$ A 2020 scoping review on OHCA in low-resource settings reported return of spontaneous circulation (ROSC) rates ranging from $0 \%$ to $62 \%$, survival to discharge rates of between $1 \%$ and $16.7 \%$, and rates of favourable neurological outcome of between $1 \%$ and $9.3 \% .{ }^{13}$ These large ranges are likely due to heterogeneity in the quality of studies reported on in the review and also the diversity of settings. Results should be interpreted with caution. Survival to hospital arrival in South Africa has been reported to be $18 \%$ in a Johannesburg-based cohort, ${ }^{2}$ yet no studies could be found reporting longerterm survival.

The vast majority of OHCAs are caused by ischaemic heart disease (IHD). ${ }^{14}$ The 
incidence of cardiovascular diseases such as IHD is on the increase in South Africa-a doubling in the incidence is expected between 1990 and 2030. ${ }^{15-17}$ Thus, despite the lack of epidemiological data on OHCA, it is certainly likely that the incidence of OHCA in South Africa is not only underestimated but also rising. This is true for the rest of sub-Sharan Africa, too. ${ }^{16-20}$

Healthcare investment and development should ideally be guided by local priorities and robust epidemiological data, and underpinned by international evidence-based guidelines. This is particularly true in settings like South Africa, and most countries on the African continent, with severely strained and limited healthcare resources. Unfortunately, there is currently a paucity of epidemiological data on OHCA within the South African and African settings. The aim of this study is therefore to describe OHCA in the City of Cape Town metropole, in the Western Cape province of South Africa.

\section{METHODOLOGY}

\section{Study design}

We undertook an observational study with a retrospective descriptive design. All OHCA data for a 1-year period (1 January 2018-31 December 2018) were extracted from the public emergency medical service (EMS) and the largest private EMS in the province.

\section{Study setting}

Covering a land mass of $129462 \mathrm{~km}^{2}$, the Western Cape province has a population of approximately 6.3 million and accounts for $11 \%$ of the total population in South Africa. Approximately $64 \%$ of the population resides in the Cape Town metropole, which has a population of just over 4 million. Regarding the most common aetiology of OHCA (ie, IHD),${ }^{14}$ it is ranked as one of the top three causes of death in the Western Cape province. ${ }^{21}$

South Africa has a dual healthcare system where insured patients are mostly treated and transported by private EMS and uninsured patients are typically transported by the provincial services as supplied by the government (public EMS). Approximately, 26.3\% of the Western Cape population has medical insurance. ${ }^{22}$ While $76.1 \%$ of the Western Cape population live with 1 hour of a facility with percutaneous coronary intervention, ${ }^{23}$ access is still not guaranteed owing to lack of medical insurance. ${ }^{24}$

The Western Cape province has a formalised tier 2 EMS ${ }^{25}$ staffed by prehospital emergency care providers at the basic (BLS), intermediate and advanced life support (ALS) ${ }^{26}$ Each ambulance is staffed by at least two providers, with ALS providers often working on rapid response vehicles. Resuscitation and defibrillation are on the scope of practice of all cadres of prehospital providers. ${ }^{27}$ Training for prehospital providers range from a 6-week (BLS) certificate course, to 4-year degree programme (ALS). Emergency call-takers are often nonmedically trained and perform their duties without a script or clear protocols on OHCA-recognition and telephonic cardiopulmonary resuscitation (CPR) guidance. ${ }^{28}$

In South Africa, there are no published registries on OHCA or public access defibrillators. There also exists no literature on the uptake of CPR training in the general population, nor is it mandated by law.

\section{Sample and sampling}

Cases of OHCA were identified in two ways, commensurate with the patient report form (PRF) archiving systems of the EMS. For the public EMS, OHCA was first identified from the computer-aided dispatch (CAD) where a patient was denoted as being 'unresponsive.' This was necessary as there was no specific 'cardiac arrest' call category. Hereafter, the unique case number was linked to the corresponding electronic patient care records, which was extracted and interrogated for the presence of OHCA.

For the private EMS, cases were identified using two methods. Any cases that were denoted as cardiac arrest or 'CPR in Progress' on the CAD system were identified and the PRF for the individual cases were extracted. Second, PRFs that were classified as resuscitation, no servicedeclaration, or were treated at an ALS level were reviewed for OHCA.

In both instances, OHCA was defined as a paramedic diagnosis of 'death,' or 'cardiac arrest,' or any instance where CPR or defibrillation was performed. We further included any patients that were unresponsive and pulseless or had a corresponding declaration of death form accompanied. Arrest location was determined by either the address given or notes related to location on the dispatch system. Where the arrest location was ambiguous or unclear, it was reported as missing. Initial rhythm was defined as the first heart rhythm reported on the patient record. Response time was defined as the time from first call in the dispatch centre to arrival on scene.

We excluded all traumatic cardiac arrests, any instances where a patient arrested in the presence of EMS, or where an ambulance unit was cancelled prior to reaching the patient.

All eligible cases were reviewed for eligibility and data were extracted by the authors WS (public EMS data) and CW (private EMS data). After extraction, a 10\% sample was drawn and reviewed against original records to ensure accuracy of data recorded.

\section{Data analysis}

After collation, data were subjected to descriptive analysis. Unfortunately, due to the small sample of patients that underwent prehospital resuscitation, and an even smaller sample of patients with ROSC, meaningful analyses between cohorts (ROSC and non-ROSC) were not possible. Group differences according to EMS sector and gender were sought using Mann-Whitney $\mathrm{U}$ test and ORs were calculated. A p-value of 0.05 was considered significant. No missing data techniques were employed. Analyses were performed using SPSS V.25 (IBM) and MedCalc Online (MedCalc Software, Ostend, Belgium). 


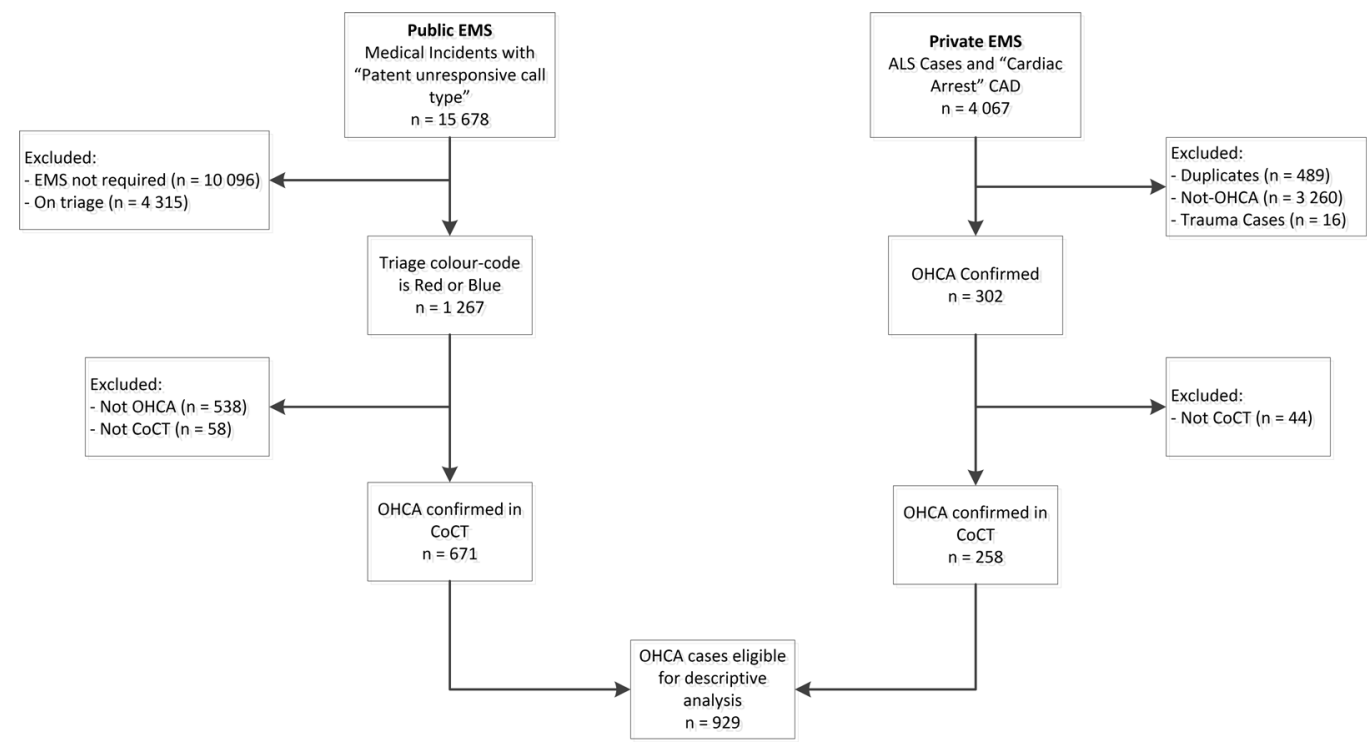

Figure 1 Case sampling and exclusion. ALS, advanced life support; CAD, computer-aided dispatch; CoCT, City of Cape Town; EMS, emergency medical services; OHCA, out-of-hospital cardiac arrest.

\section{Patient and public involvement}

Due to the retrospective nature of this study, no patients were involved. However, this study will inform ongoing community and stakeholder engagement work for patients at risk of OHCA.

\section{RESULTS}

For the period of 1 January 2018-31 December 2018, a total of 929 patients with OHCA received an EMS response in the City of Cape Town metropole, corresponding to an annual prevalence of 23.2 per 100000 persons. Figure 1 outlines the selection of cases. Table 1 describes the characteristics of patients with OHCA.

Most patients were adult $(\mathrm{n}=885 ; 96.5 \%)$ and male $(\mathrm{n}=526 ; 56.6 \%)$ with a median (IQR) age of 63 (26) years. Figure 2 outlines the distribution of patient age. The majority of cardiac arrests occurred in private residences $(\mathrm{n}=740 ; 79.7 \%)$ and presented with asystole $(\mathrm{n}=322$; $34.6 \%)$. However, in $61.8 \%(\mathrm{n}=574)$ of cases, the initial rhythm was not recorded. All patients who presented with a shockable rhythm $(\mathrm{n}=16 ; 1.7 \%)$ received defibrillation by EMS. Resuscitation by the responding EMS was only attempted in $7.4 \% \quad(\mathrm{n}=69)$ of cases and ROSC only occurred in $1.3 \% \quad(n=13)$ of all cases, all of which were resuscitated by EMS. Therefore, $18.8 \%$ of patients who were resuscitated achieved ROSC. A small number of patients $(\mathrm{n}=7 ; 0.75 \%)$ were transported to a health facility while still being resuscitated, while almost all patients $(\mathrm{n}=909 ; 97.8 \%)$ were declared dead on the scene of the OHCA. Response times were $17 \mathrm{~min}$ and $32 \mathrm{~s}$ for those patients where resuscitation was attempted, vs $27 \mathrm{~min}$ and $13 \mathrm{~s}$ in those that were not.

Table 2 describe the characteristics of OHCA when those occurring in the public and private sector are compared. Missingness is reported as proportion of those with sector recorded. Patients with OHCA were significantly younger in the private sector ( 59 vs 75 years; $\mathrm{p}<0.01$ ), and had a higher incidence of ROSC ( $4.3 \%$ vs $0.3 \%$; OR $(95 \% \mathrm{CI})$ $0.07(0.01$ to $0.31, \mathrm{p}<0.01)$ ). Resuscitation occurred more commonly (table 1) in the private sector than public sector EMS ( $17.1 \%$ vs $3.7 \%$; OR $(95 \% \mathrm{CI}) 0.19$ (0.11 to $0.31, \mathrm{p}<0.01)$ ). Similarly, the response time was significantly shorter in the private sector than the public sector EMS (10:00 vs 20.39; $p<0.01)$. The incidence of shockable rhythm and arresting in a public location was not related to the EMS sector (all $\mathrm{p}>0.05$ ).

Table 3 describes the characteristics of OHCA according to sex as assigned by the prehospital providers. Missingness is reported as proportion of those with sex recorded. Male patients were significantly younger than female patients ( 60 vs 67 years; $\mathrm{p}<0.01$ ) and were more likely to arrest in a public location $(13.3 \%$ vs $6.6 \%$; OR $(95 \% \mathrm{CI})$ $0.45(0.28$ to $0.72, \mathrm{p}<0.01))$. Initial response time, initial rhythm and outcome were similar across the sexes (all $\mathrm{p}>0.05)$.

Regarding compliance with the Utstein reporting variables,$^{29}$ dispatcher core variables (identification and telephonic CPR instructions) were not recorded in any cases, core patient variables were missing in $0.01 \%(\mathrm{n}=7)$ of cases for age and $1 \%(n=9)$ of cases for sex. Whether an arrest was witnessed or not and whether bystanders provided any care to victims were not explicitly recorded. The location of the arrest was not apparent in $9.7 \%$ $(\mathrm{n}=90)$ of cases. An overwhelming majority of OHCAs $(\mathrm{n}=574 ; 61.8 \%)$ had no initial rhythm recorded. Lastly, as only short-term outcomes were assessed in this study, other postresuscitation variables were not recorded.

\section{DISCUSSION}

This study aimed to retrospectively describe cases of OHCA in a single city in South Africa. Most patients were adult, middle-aged men, who arrested in a private 
Table 1 Characteristics of OHCA cases, shown by EMS treatment

\begin{tabular}{|c|c|c|c|c|}
\hline & Overall, $n=929$ & $\begin{array}{l}\text { EMS treated, } \mathrm{n}(\%) \\
69(7.4 \%)\end{array}$ & $\begin{array}{l}\text { EMS not-treated, n (\%) } \\
860(92.6 \%)\end{array}$ & Missing, n (\%) \\
\hline Age, median (IQR) & 63 (26) years & 63 (21) years & 63 (27) years & $7(0.01)$ \\
\hline Adult, n (\%) & $885(96.5)$ & $62(90)$ & $823(95.7)$ & $12(1.3)$ \\
\hline Paediatric, n (\%) & $18(2)$ & $3(4.3)$ & $15(1.7)$ & \\
\hline Infant (<1 year), n (\%) & $14(1.5)$ & $2(2.9)$ & $12(1.4)$ & \\
\hline Sex, n (\%) & & & & $9(1 \%)$ \\
\hline Male, n (\%) & $526(56.6)$ & $42(60.9)$ & $484(56.3)$ & \\
\hline Female, n (\%) & $394(42.1)$ & $26(37.7)$ & $368(42.8)$ & \\
\hline \multicolumn{5}{|l|}{ EMS sector } \\
\hline Private, n (\%) & $258(27.8)$ & $44(17.1)$ & 214 (82.9) & \\
\hline Public, n (\%) & 671 (72.2) & $25(3.7)$ & $646(96.3)$ & \\
\hline Arrest location & & & & $90(9.7)$ \\
\hline Public, n (\%) & $99(10.7)$ & 22 (31.9) & $77(9.0)$ & \\
\hline Private, n (\%) & $740(79.7)$ & $45(65.2)$ & $695(80.8)$ & \\
\hline Response time, mm:ss & $26: 30$ & $17: 32$ & $27: 13$ & 0 \\
\hline Initial rhythm & & & & $574(61.8)$ \\
\hline VF, n (\%) & $16(1.7)$ & $16(23.2)$ & 0 & \\
\hline PEA, n (\%) & $17(1.8)$ & $17(24.6)$ & 0 & \\
\hline Asystole, n (\%) & $322(34.6)$ & $27(39)$ & $295(34.3)$ & \\
\hline Outcome & & & & 0 \\
\hline ROSC & $13(1.3)$ & $13(18.8)$ & 0 & \\
\hline Transported, no ROSC & $7(0.75)$ & $7(10.1)$ & 0 & \\
\hline Declared on scene & $909(97.8)$ & $49(71.0)$ & $860(100)$ & \\
\hline
\end{tabular}

EMS, emergency medical services; OHCA, out-of-hospital cardiac arrest; PEA, Pulseless electrical activity; ROSC, return of spontaneous circulation; VF, ventricular fibrillation.

setting and presented with a non-shockable cardiac arrest rhythm. Resuscitation was attempted in less than one in ten patients during this 1-year period. Incidents of OHCA were also characterised by prolonged response times, which may explain these results.

In this study, the incidence of OHCA in the Cape Town metropole was considerably higher $(23.2 / 100000)$ than that reported in a Johannesburg cohort (6.4/100 000) and is likely related to the data sources used to determine the incidence (the Johannesburg study used a paramedic student database). ${ }^{2}$ Yet, this is similar to that reported

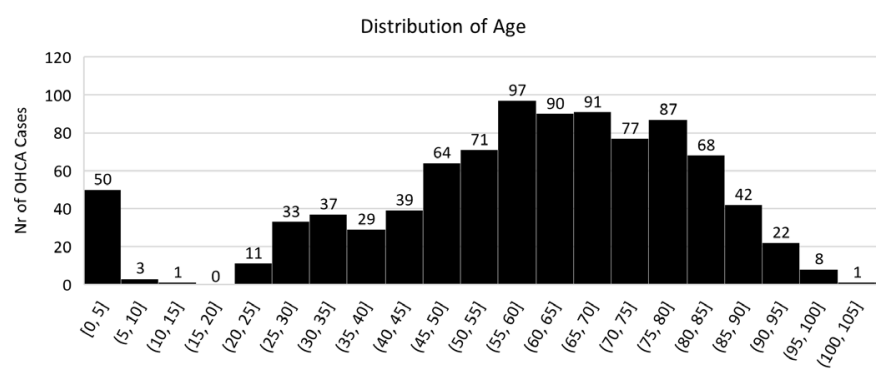

Age in years

Figure 2 Distribution of age of patients with OHCA. OHCA, out-of-hospital cardiac arrest. in an Asian study (28.3/100 000). ${ }^{7}$ While not explicitly OHCA, a Cameroonian study showed an incidence of sudden cardiac death of 24.2/100 $000 .{ }^{30}$ The incidence of OHCA in our study is much lower than that reported in Europe which ranges from 53 to $166 / 100000 .^{31}$ This difference may be explained by the retrospective nature of our study, narrow inclusion criteria and general poor reporting on OHCA across systems.

The majority of patients in this study were middle-aged, with a male predominance. Patient demographics in the present study are similar to that observed in previous studies in high ${ }^{31} 32$ and low- to middle income country $(\mathrm{LMIC})^{11}$ settings. This also represents the patient cohort that is most likely to have IHD. ${ }^{2033}$ This supports the idea that the epidemiology of OHCA, in line with that of IHD, is likely on the increase in sub-Saharan populations. ${ }^{15-17}$

Resuscitation by EMS was attempted in very few patients. While it is unclear why this is the case, some explanations are likely. First, this may be a reflection of prolonged response times and poor initiation of bystander CPR, leading to poor patient prognosis and the decision by EMS to withhold resuscitation attempts. It is suggested that qualitative research seeks to understand what factors 
Table 2 Characteristics of OHCA cases, shown by EMS sector (private vs public)

\begin{tabular}{|c|c|c|}
\hline & $\begin{array}{l}\text { Private EMS, } \\
\text { n (\%) } \\
258(27.8 \%)\end{array}$ & $\begin{array}{l}\text { Public EMS, } \\
\text { n (\%) } \\
671(72.2 \%)\end{array}$ \\
\hline Age, median (IQR) & $59(22)$ & $75(21)$ \\
\hline Adult, n (\%) & $251(97.3)$ & $634(94.5)$ \\
\hline Paediatric, n (\%) & $2(0.8)$ & $16(2.4)$ \\
\hline Infant (<1 year), $\mathrm{n}(\%)$ & $2(0.8)$ & $12(1.8)$ \\
\hline Missing, n (\%) & $3(1.1)$ & $15(2.2)$ \\
\hline \multicolumn{3}{|l|}{ Sex, n (\%) } \\
\hline Male, n (\%) & $145(56.2)$ & $381(56.8)$ \\
\hline Female, n (\%) & $113(43.8)$ & $281(41.9)$ \\
\hline Missing, n (\%) & $0(0)$ & $9(1.3)$ \\
\hline \multicolumn{3}{|l|}{ Arrest location } \\
\hline Public, n (\%) & $33(12.8)$ & $66(9.8)$ \\
\hline Private, n (\%) & 225 (87.2) & $515(76.8)$ \\
\hline Missing, n (\%) & $0(0)$ & $90(13.4)$ \\
\hline Response time, mm:ss & $10: 00$ & 20:39 \\
\hline \multicolumn{3}{|l|}{ Initial rhythm } \\
\hline VF, n (\%) & $14(5.4)$ & $2(0.3)$ \\
\hline PEA, n (\%) & $11(4.3)$ & $6(0.9)$ \\
\hline Asystole, n (\%) & $232(89.9)$ & $90(13.4)$ \\
\hline Missing, n (\%) & $1(0.4)$ & $573(85.4)$ \\
\hline \multicolumn{3}{|l|}{ Outcome } \\
\hline ROSC & $11(4.3)$ & $2(0.3)$ \\
\hline Transported, no ROSC & $2(0.8)$ & $5(0.7)$ \\
\hline Declared on scene & 245 (94.9) & 664 (99.0) \\
\hline
\end{tabular}

EMS, emergency medical services; OHCA, out-of-hospital cardiac arrest; PEA, pulseless electrical activity; ROSC, return of spontaneous circulation; VF, ventricular fibrillation.

EMS personnel use to base their decision to initiate or withhold resuscitation.

Second, the response times in this study were much longer $(26 \mathrm{~min})$ than in other settings where response times to OHCA were 6 min in Iran, ${ }^{34} 7$ min in Sweden ${ }^{35}$ and Serbia, ${ }^{36}$ and $21 \mathrm{~min}$ in Lebanon. ${ }^{37}$ The only other South African OHCA study reported a response time of 9 min. ${ }^{2}$ Importantly, however, is that this study defined response times as the interval between emergency vehicle dispatch and arrival at the scene time, and therefore leads to a rather gross underestimation. It has been suggested that the odds of survival may increase by $24 \%{ }^{38}$ and favourable neurological outcome by $13 \%,{ }^{39}$ with every $1 \mathrm{~min}$ decrease in response time to OHCA. Yet, at a projected cost of $£ 54$ million, this is an impossible task for resourceconstrained healthcare settings, such as South Africa. ${ }^{38}$

A third reason for such low rates of resuscitation which may also explain the response times, is the role of the EMS in performing out-of-hospital declarations of death. In the South African setting, EMS personnel are licensed
Table 3 Characteristics of OHCA cases, shown by sex

Male, $\mathbf{n}(\%) \quad$ Female, $\mathbf{n}(\%)$

$526(56.6 \%) \quad 394(42.1 \%)$

\begin{tabular}{|lcc|}
\hline Age, median (IQR) & $60(15)$ & $67(27)$ \\
\hline Adult, $\mathrm{n}(\%)$ & $507(96.4)$ & $376(95,4)$ \\
\hline Paediatric, $\mathrm{n}(\%)$ & $9(1.7)$ & $9(2.3)$ \\
Infant (<1 year), $\mathrm{n}(\%)$ & $6(1.1)$ & $8(2.0)$ \\
\hline Missing, $\mathrm{n}(\%)$ & $4(0.2)$ & $1(0.3)$ \\
\hline
\end{tabular}

Arrest location

$\begin{array}{ccc}\text { Public, } \mathrm{n}(\%) & 70(13.3) & 26(6.6) \\ \text { Private, } \mathrm{n}(\%) & 401(76.2) & 334(84.8) \\ \text { Missing, } \mathrm{n}(\%) & 55(10.5 \%) & 34(8.6) \\ \text { Response time, mm:ss } & 17: 33 & 16: 07\end{array}$

Initial rhythm

\begin{tabular}{lcc} 
VF, $\mathrm{n}(\%)$ & $11(2.1)$ & $5(1.3)$ \\
PEA, n (\%) & $10(1.9)$ & $7(1.8)$ \\
Asystole, n (\%) & $179(34.0)$ & $142(36.0)$ \\
Missing, $\mathrm{n}(\%)$ & $326(62.0)$ & $240(60.9)$ \\
Outcome & & \\
ROSC & $9(1.7)$ & $4(1.0)$ \\
Transported, no ROSC & $5(1.0)$ & $2(0.5)$ \\
Declared on scene & $512(97.3)$ & $388(98.5)$ \\
\hline
\end{tabular}

OHCA, out-of-hospital cardiac arrest; PEA, pulseless electrical activity; ROSC, return of spontaneous circulation; VF, ventricular fibrillation.

to declare patients dead before corpses may be removed from a private or public space. It is unclear how many of these EMS responses were for incidents where a declaration of death was sought, rather than active emergency care. When a declaration is requested, the case will be delayed until other emergency incidents have been serviced before sending a vehicle to the scene. Means of excluding these cases should be sought in future studies from this setting.

Response times were significantly shorter in the private sector EMS, who were also more likely to initiate resuscitation. Shorter responses in private healthcare may be reflective of the number of resources available-healthcare expenditure in the private sector is up to 10 times more per capita in South Africa than that reported for the public sector. ${ }^{40}$ Patients in the private sector were also significantly younger, which may have affected prehospital provider decisions to initiate resuscitation, explaining the higher rates of ROSC. Factors that influence decisionmaking may further be explored qualitatively.

Similar to papers published elsewhere, ${ }^{11} 31353742$ very few OHCAs occurred in public places. Very little data are available on the amounts and locations of public access automated external defibrillators (AEDs) on the continent. This may negate the impact of mass public CPR campaigns and large public access AED programmes, 
which have been suggested as effective interventions in improving OHCA survival. ${ }^{43} 44$ These interventions may therefore not be cost effective in low-resource settings such as South Africa. Community CPR campaigns have been demonstrated to cost between US $\$ 22539^{45}$ and US\$62 $600^{46}$ per quality-adjusted life-year gained, while public access AEDs show that it will cost between US $\$ 30$ $000^{47}$ and US $\$ 1102473^{48}$ per quality-adjusted life-year gained. Yet, as increased incidence in OHCA is expected, some interventions should be invested in to manage such patients. Perhaps, a tailored approach to high-risk communities should be developed to ensure a yield with limited available resources. One such option may be telephone-assisted CPR (tCPR), which has been shown to be cost-effective and to significantly improve bystander CPR rates. ${ }^{49}$ However, there is a dearth of African data on the acceptability of tCPR as well as dispatch recognition of OHCA and future studies should investigate these elements of the Chain of Survival. Similarly, future studies should investigate the willingness of bystanders within these settings to perform bystander CPR.

While only prehospital survival (ie, ROSC rates) were investigated in this study, the number of patients who achieved ROSC was almost negligible. This is similar to other studies from low resource settings. ${ }^{13}$ This is likely as a consequence of the low resuscitation rates and prolonged response times in the city of Cape Town. Based on the cost effectiveness of mass CPR and AED programmes, and emergency and intensive care resources available in LMICs, like South Africa; as well as the ROSC rates observed in this study and that from other LMICs, it is essential to develop innovative interventions for OHCA that may maximise outcome and resource utility. Such interventions should also be contextually appropriate given the disease and injury burden of the setting and the sociocultural elements of the society. All of this should be underpinned by the latest evidence and appropriate engagement with healthcare providers, policy-makers and community members from such settings.

\section{Limitations}

This study is limited by its retrospective design and lack of compliance to the Utstein OHCA reporting guidelines. South Africa lacks a prospective OHCA registry and, thus, the variables that may be reported on are limited to those recorded on clinical notes. Further, in the absence of clear emergency call categories for OHCA, it is possible that some OHCA cases could have not been sampled. There are also smaller private services in the Western Cape that were not sampled, and this might lead to a somewhat underestimation of the incidence of OHCA.

The relatively small sample size of patients with ROSC and those that were transported, as well as lack of longer-term outcome data, meant that more granular subanalyses were not possible. We suggest the development and implementation of an OHCA registry for the city. This will also affect the rate of missingness, which is higher in the public sector and might also be related to resource availability (eg, the availability of portable electrocardiographs).

\section{CONCLUSION}

To our knowledge, this was the largest study investigating the incidence and prehospital outcome of OHCA ever undertaken in Africa. We found that while the incidence of OHCA in Cape Town was similar to that described in the literature, resuscitation is attempted in very few patients, and ROSC-rates are negligible. This is likely as a consequence of prolonged response times or assessments of poor prognosis by prehospital providers. This may also be as a consequence of an underdeveloped and underresourced Chain of Survival in LMICs like South Africa.

Owing to an increase in cardiovascular diseases in subSaharan Africa, the incidence of OHCA is likely to increase in the coming decades. For this reason, it is essential to develop contextual guidelines for these settings that are contextually appropriate given the disease and injury burden of the setting and the sociocultural elements of the society.

Twitter Willem Stassen @willem_stassen

Contributors Study concept and design: WS and TD. Acquisition of data: WS and CW. Analysis and interpretation of data: WS, CW, TD and LAW. Drafting of the manuscript: WS, CW and LAW. Critical revision of the manuscript for important intellectual content: WS, CW, TD and LAW.

Funding The authors have not declared a specific grant for this research from any funding agency in the public, commercial or not-for-profit sectors.

Competing interests None declared.

Patient and public involvement Patients and/or the public were not involved in the design, or conduct, or reporting, or dissemination plans of this research.

Patient consent for publication Not required.

Ethics approval Ethical approval for this study was obtained from the Human Research Ethics Committee of the University of Cape Town (HREC Ref: 791/2018) and from the public and private EMS organisations. The study was approved with waiver of informed consent and all data were anonymised.

Provenance and peer review Not commissioned; externally peer reviewed.

Data availability statement Data are available on reasonable request. Data supporting the findings of this study is available on reasonable request and subject to approval and restrictions by the respective emergency medical services, the data owners.

Open access This is an open access article distributed in accordance with the Creative Commons Attribution Non Commercial (CC BY-NC 4.0) license, which permits others to distribute, remix, adapt, build upon this work non-commercially, and license their derivative works on different terms, provided the original work is properly cited, appropriate credit is given, any changes made indicated, and the use is non-commercial. See: http://creativecommons.org/licenses/by-nc/4.0/.

\section{ORCID iDs}

Willem Stassen http://orcid.org/0000-0002-1486-4446

Lee A Wallis http://orcid.org/0000-0003-2711-3139

\section{REFERENCES}

1 Rajagopal S, Booth SJ, Brown TP, et al. Data quality and 30day survival for out-of-hospital cardiac arrest in the UK out-ofhospital cardiac arrest registry: a data linkage study. BMJ Open 2017;7:e017784. doi:10.1136/bmjopen-2017-017784

2 Stein C. Out-of-hospital cardiac arrest cases in Johannesburg, South Africa: a first glimpse of short-term outcomes from a paramedic 
clinical learning database. Emerg Med J 2009;26:670-4. doi:10.1136/ emj.2008.066084

3 Veronese J-P, Wallis L, Allgaier R, et al. Cardiopulmonary resuscitation by emergency medical services in South Africa: barriers to achieving high quality performance. Afr J Emerg Med 2018;8:6-11. doi:10.1016/j.afjem.2017.08.005

4 Zwingmann J, Mehlhorn AT, Hammer T, et al. Survival and neurologic outcome after traumatic out-of-hospital cardiopulmonary arrest in a pediatric and adult population: a systematic review. Crit Care 2012:16:R117. doi:10.1186/cc11410

5 El Sayed M, Al Assad R, Abi Aad Y, et al. Measuring the impact of emergency medical services (EMS) on out-of-hospital cardiac arrest survival in a developing country. Medicine 2017;96:e7570.

6 Savastano S, Klersy C, Raimondi M, et al. Positive trend in survival to hospital discharge after out-of-hospital cardiac arrest: a quantitative review of the literature. J Cardiovasc Med 2014;15:609-15. doi:10.2459/JCM.0000000000000040

7 Berdowski J, Berg RA, Tijssen JGP, et al. Global incidences of outof-hospital cardiac arrest and survival rates: systematic review of 67 prospective studies. Resuscitation 2010;81:1479-87. doi:10.1016/j. resuscitation.2010.08.006

8 Kitamura T, Kiyohara K, Sakai T, et al. Epidemiology and outcome of adult out-of-hospital cardiac arrest of non-cardiac origin in Osaka: a population-based study. BMJ Open 2014;4:e006462. doi:10.1136/ bmjopen-2014-006462

9 Hawkes C, Booth S, Ji C, et al. Epidemiology and outcomes from out-of-hospital cardiac arrests in England. Resuscitation 2017;110:133-40. doi:10.1016/j.resuscitation.2016.10.030

10 Bonny A, Ngantcha M, Amougou SN, et al. Rationale and design of the Pan-African sudden cardiac death survey: the Pan-African SCD study. Cardiovasc J Afr 2014:25:176-84.

11 Mawani M, Kadir MM, Azam I, et al. Epidemiology and outcomes of out-of-hospital cardiac arrest in a developing country-a multicenter cohort study. BMC Emerg Med 2016;16:28.

12 Bonny A, Ngantcha M, Scholtz W, et al. Cardiac arrhythmias in Africa. J Am Coll Cardiol 2019;73:100-9.

13 Schnaubelt S, Monsieurs KG, Semeraro F, et al. Clinical outcomes from out-of-hospital cardiac arrest in low-resource settings - A scoping review. Resuscitation 2020;156:137-45.

14 Myat A, Song K-J, Rea T. Out-of-hospital cardiac arrest: current concepts. Lancet 2018;391:970-9. doi:10.1016/S01406736(18)30472-0

15 Mayosi BM, Flisher AJ, Lalloo UG, et al. The burden of noncommunicable diseases in South Africa. Lancet 2009;374:934-47. doi:10.1016/S0140-6736(09)61087-4

16 Hertz JT, Reardon JM, Rodrigues CG, et al. Acute myocardial infarction in sub-Saharan Africa: the need for data. PLoS One 2014;9:e96688. doi:10.1371/journal.pone.0096688

17 Ikem I, Sumpio BE. Cardiovascular disease: the new epidemic in sub-Saharan Africa. Vascular 2011;19:301-7. doi:10.1258/vasc.2011. ra0049

18 Mbewu A. The burden of cardiovascular disease in sub-Saharan Africa. SA Hear 2009;6:4-10.

19 Gaziano TA. Reducing the growing burden of cardiovascular disease in the developing world. Health Aff 2007;26:13-24. doi:10.1377/ hlthaff.26.1.13

20 Onen CL. Epidemiology of ischaemic heart disease in sub-Saharan Africa. Cardiovasc J Afr 2013;24:34-42. doi:10.5830/CVJA-2012-071

21 P0309. STATISTICAL RELEASE Mortality and causes of death in South Africa. Findings from death notification [online], 2016. Available: www.statssa.gov.zainfo@statssa.gov.za

22 Statistics SA. General household survey 2014, 2015.

23 Stassen W, Wallis L, Vincent-Lambert C, et al. The proportion of South Africans living within 60 and 120 minutes of a percutaneous coronary intervention facility. Cardiovasc J Afr 2018;29:6-11.

24 Stassen W, Wallis L, Lambert C, et al. Percutaneous coronary intervention still not accessible for many South Africans. Afr J Emerg Med 2017;7:105-7.

25 Stein C, Mould-Millman N-K, De Vries S, et al. Access to outof-hospital emergency care in Africa: consensus conference recommendations. Afr J Emerg Med 2016;6:158-61. doi:10.1016/j. afjem.2016.08.008

26 Mould-Millman NK, Stein C, Wallis LA. Time to standardise levels of care amongst out-of-hospital emergency care providers in Africa. Afr J Emerg Med 2016;6:54-5.

27 Health Professions Council of South Africa. Clinical practice guidelines for emergency care providers [online], 2018. Available: https://www.hpcsa.co.za/Uploads/EMB/CLINICAL PRACTICE GUIDELINES - PROTOCOLS- JULY 2018.pdf

28 van Rensburg LC, Richmond L, Mgidi S, et al. The lay descriptors of out-of-hospital cardiac arrest in the Western Cape Province,
South Africa. Resusc Plus 2021;7:100146. doi:10.1016/j. resplu.2021.100146

29 Perkins GD, Jacobs IG, Nadkarni VM, et al. Cardiac arrest and cardiopulmonary resuscitation outcome reports: update of the Utstein resuscitation registry templates for out-of-hospital cardiac arrest. Circulation 2015;132:1286-300. doi:10.1161/ CIR.0000000000000144

30 Bonny A, Tibazarwa K, Mbouh S, et al. Epidemiology of sudden cardiac death in Cameroon: the first population-based cohort survey in sub-Saharan Africa. Int J Epidemiol 2017;46:1230-8. doi:10.1093/ $\mathrm{ije} / \mathrm{dyx} 043$

31 Gräsner J-T, Herlitz J, Tjelmeland IBM, et al. European resuscitation Council guidelines 2021: epidemiology of cardiac arrest in Europe. Resuscitation 2021;161:61-79. doi:10.1016/j. resuscitation.2021.02.007

32 Luc G, Baert V, Escutnaire J, et al. Epidemiology of out-of-hospital cardiac arrest: a French national incidence and mid-term survival rate study. Anaesth Crit Care Pain Med 2019;38:131-5. doi:10.1016/j. accpm.2018.04.006

33 Yuyun MF, Sliwa K, Kengne AP, et al. Cardiovascular diseases in sub-Saharan Africa compared to high-income countries: an epidemiological perspective. Glob Heart 2020;15:15. doi:10.5334/ gh.403

34 Navab E, Esmaeili M, Poorkhorshidi N, et al. Predictors of out of hospital cardiac arrest outcomes in pre-hospital settings; a retrospective cross-sectional study. Arch Acad Emerg Med 2019;7:36.

35 Riva G, Ringh M, Jonsson M, et al. Survival in out-of-hospital cardiac arrest after standard cardiopulmonary resuscitation or chest compressions only before arrival of emergency medical services. Circulation 2019;139:2600-9. doi:10.1161/ CIRCULATIONAHA.118.038179

36 Sladjana A, Gordana P, Ana S. Emergency response time after out-of-hospital cardiac arrest. Eur J Intern Med 2011;22:386-93. doi:10.1016/j.ejim.2011.04.003

37 Refaat MM, Kozhaya K, Abou-Zeid F, et al. Epidemiology, etiology, and outcomes of out-of-hospital cardiac arrest in young patients in Lebanon. Pac Clin Electrophysiol 2019;42:1390-5. doi:10.1111/ pace.13801

38 O'Keeffe C, Nicholl J, Turner J, et al. Role of ambulance response times in the survival of patients with out-of-hospital cardiac arrest. Emerg Med J 2011:28:703-6. doi:10.1136/emj.2009.086363

39 Guy A, Kawano T, Besserer F, et al. The relationship between noflow interval and survival with favourable neurological outcome in out-of-hospital cardiac arrest: implications for outcomes and ECPR eligibility. Resuscitation 2020;155:219-25. doi:10.1016/j. resuscitation.2020.06.009

40 Harris B, Goudge J, Ataguba JE, et al. Inequities in access to health care in South Africa. $J$ Public Health Policy 2011;32:S102-23. doi:10.1057/jphp.2011.35

41 Mayosi BM, Benatar SR. Health and health care in South Africa - 20 years after Mandela. N Engl J Med Overseas Ed 2014;371:1344-53. doi:10.1056/NEJMsr1405012

42 Krishna CK, Showkat HI, Taktani M, et al. Out of hospital cardiac arrest resuscitation outcome in North India - CARO study. World J Emerg Med 2017;8:200-5. doi:10.5847/ wjem.j.1920-8642.2017.03.007

43 Panchal AR, Bartos JA, Cabañas JG, et al. Part 3: adult basic and advanced life support: 2020 American heart association guidelines for cardiopulmonary resuscitation and emergency cardiovascular care. Circulation 2020;142:S366-468.

44 Berg KM, Cheng A, Panchal AR, et al. Part 7: systems of care: 2020 American heart association guidelines for cardiopulmonary resuscitation and emergency cardiovascular care. Circulation 2020;142:S580-604. doi:10.1161/CIR.0000000000000899

45 Bouland AJ, Risko N, Lawner BJ, et al. The price of a helping hand: modeling the outcomes and costs of bystander CPR. Prehosp Emerg Care 2015;19:524-34. doi:10.3109/10903127.2014.995844

46 Nichol G, Huszti E, Birnbaum A, et al. Cost-Effectiveness of lay Responder defibrillation for out-of-hospital cardiac arrest. Ann Emerg Med 2009;54:226-35. doi:10.1016/j.annemergmed.2009.01.021

47 Cram P, Vijan S, Fendrick AM. Cost-effectiveness of automated external defibrillator deployment in selected public locations. J Gen Intern Med 2003;18:745-54. doi:10.1046/j.1525-1497.2003.21139.x

48 Moran PS, Teljeur C, Masterson S, et al. Cost-effectiveness of a national public access defibrillation programme. Resuscitation 2015;91:48-55. doi:10.1016/..resuscitation.2015.03.017

49 Kurz MC, Bobrow BJ, Buckingham J, et al. Telecommunicator cardiopulmonary resuscitation: a policy statement from the American heart association. Circulation 2020;141. doi:10.1161/ CIR.0000000000000744 